\title{
Análisis del presupuesto aprobado y del gasto ejercido, 2001-2017. El caso del Ramo 33
}

\section{Analysis of the Approved Budget and the Executed Spending, 2001-2017. The Case of Ramo 33}

\author{
Said Sánchez* (iD https://orcid.org/0000-0003-4887-0817
}

\section{Resumen}

Algunas investigaciones han mostrado que el gobierno federal gasta más de lo establecido en el presupuesto de egresos. En el caso de las trasferencias federales, la evidencia aún es escasa. Por lo tanto, los objetivos de esta investigación son mostrar datos sobre la diferencia entre el presupuesto y el gasto ejercido del Ramo 33 en el periodo 200I-20I7; destacar cómo se distribuye entre los estados; y determinar si la alineación partidista vertical incide en su repartición. Mediante un análisis de tipo panel, los resultados muestran que hay un sobreejercicio del gasto del Ramo 33, pero la alineación partidista vertical no tiene un efecto en él. En suma, no hay una influencia partidista en la distribución de estos recursos.

Palabras clave: Ramo 33; gasto presupuestado; gasto ejercido; alineación partidista vertical.

\begin{abstract}
Some scholars have shown that federal government spends more than what the expenditure budget entitles. In the case of federal transfers, the evidence is limited. Therefore, the aims of the study are to show evidence of the difference between the approved Budget and the executed Spending of the Ramo 33 during 200I-20I7; to highlight how the difference allocation was made among the states; and to determine whether vertical partisan alignment has an effect on this allocation or not. Using a panel data analysis, the results show that the federal government allocates more resources than the approved Budget; but the vertical partisan alignment has not an effect. To sum up, there is not a partisan influence in the distribution of these resources.

Keywords: Ramo 33; Approved Budget; Executed Budget; Vertical Partisan Alignment.
\end{abstract}

Cómo citar: Sánchez, S. (2020). Análisis del presupuesto aprobado y del gasto ejercido, 200I-20I7. El caso del Ramo 33. región y sociedad, 32, el270. doi: I0.22/98/rys2020/32/I 270

*El Colegio de Jalisco, A. C., Calle 5 de Mayo Núm. 321, Loma Blanca, C. P. 45100, Zapopan, Jalisco, México. Correo electrónico: said.sanchez@coljal.edu.mx

Recibido: 25 de noviembre de 2019

Aceptado: 3 de junio de 2020

Liberado: 19 de junio de 2020

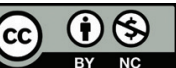

Esta obra está protegida bajo una Licencia

Creative Commons Atribución-No Comercial

4.0 Internacional. 


\section{Introducción}

El Presupuesto de Egresos de la Federación (PEF) es un documento en el que el gobierno federal mexicano establece sus prioridades de gasto. Como todo plan, puede ser modificado durante su ejercicio. En efecto, varias investigaciones han demostrado que dicho gobierno gasta más de lo que se establece en el PEF (Diaz-Cayeros y Magaloni, 1998; México Evalúa, 2014, 2018a, 2018b; Núñez, 2017; Ugalde, 2018). Por ejemplo, se sabe que entre 2000 y 2016, el gobierno federal ejerció, en promedio, 7\% más (Núñez, 2017). Para tener una idea de la magnitud de este porcentaje, en el año fiscal de 2017, el gobierno federal gastó de forma adicional alrededor de 367 mil millones de pesos, es decir, poco más del triple del presupuesto para el estado de Jalisco en el mismo año (a precios corrientes). Este tipo de comportamiento no es reciente, ya que también se dio en las últimas décadas del siglo XX (Diaz-Cayeros y Magaloni, 1998).

Aunque los estudios señalados se enfocan en el gasto total, también se ha observado un comportamiento similar en el caso del gasto federalizado, es decir, aquel que se trasfiere del gobierno federal a los gobiernos subnacionales. Una de las primeras investigaciones mostró que, entre 1970 y 1993, algunos estados recibieron más recursos que los presupuestados, mientras que otros recibieron cantidades menores (Diaz-Cayeros, 1997). ${ }^{1}$ Recientemente, se ha documentado que hay diferencias entre los montos presupuestados del gasto federalizado y lo que en realidad se ha ejercido, por ejemplo en los Ramos 23, 28 y 33 (México Evalúa, 2014, 2018a). ${ }^{2}$ Además, en el caso del Ramo 23, se detectó la influencia de variables partidistas en su comportamiento. ${ }^{3}$

Los estudios anteriores destacan que hay diferencia entre el presupuesto y el gasto ejercido. Pero ¿por qué preocuparse de esta diferencia? Hay dos razones. En primer lugar, se considera un indicador de la capacidad del gobierno para diseñar presupuestos confiables y realistas. Esta variable se retoma en uno de los Objetivos de Desarrollo Sostenible de la Organización de las Naciones Unidas (ONU). En él se incluye el indicador de gasto del gobierno como proporción del presupuesto original aprobado, sobre el que se destaca que, para ser una base sólida para el desarrollo, los presupuestos deben ser exhaustivos, trasparentes y realistas (ONU, 2017). Así mismo, el Programa de Gasto Público y Rendición de Cuentas (PEFA, por sus siglas en inglés) ${ }^{4}$ considera este aspecto en sus evaluaciones internacionales sobre el manejo de las finanzas públicas (PEFA, 2016).

1 En un estudio previo (Molinar y Weldon, 1994) se mostró que los recursos del Programa Nacional de Solidaridad (PRONASOL) se distribuían con sesgos partidistas y electorales.

2 Por medio de estos ramos, el gobierno federal trasfiere recursos a estados y municipios. Más adelante se dan detalles sobre los ramos 28 y 33.

3 La distancia entre lo presupuestado y lo ejercido del gasto federalizado no es el único aspecto que llama la atención; también se ha puesto el acento en la deficiente normatividad para regular el ejercicio trasparente de estos recursos. En el caso del Ramo 33, se destaca que si bien "está normado en la Ley de Coordinación Fiscal, lo está de manera básica, ya que esta Ley solamente se enfoca en regular algunas de sus asignaciones, sin hacer mención de las posibles adecuaciones que pueda experimentar durante el ejercicio" (México Evalúa, 2014, p. 28).

4 El PEFA es una asociación de donantes creada en 2001, integrada por el Banco Mundial, la Comisión Europea, el Fondo Monetario Internacional y diversos gobiernos europeos. 
Para el PEFA, una diferencia entre el presupuesto y el gasto ejercido mayor a $+15 \%$ es una mala práctica en términos de planeación y confiabilidad del gasto público.

En segundo lugar, esta diferencia puede indicar las fallas en el sistema de pesos y contrapesos. En el caso del gobierno federal mexicano, se ha subrayado que el poder ejecutivo tiene un amplio margen de maniobra para modificar el presupuesto; que los presupuestos son poco confiables debido a las modificaciones; que no hay mecanismos para controlar y dar certidumbre al proceso de ejecución; y que el poder legislativo tiene un papel débil en la fase del ejercicio del gasto, entre otras deficiencias (México Evalúa, 2014, 2018a; Núñez, 2017; PEFA, 2012; Ugalde, 2018). La diferencia entre el presupuesto y lo que en realidad se gasta también se ha visto como un indicador de la discrecionalidad en el uso de los recursos públicos (Diaz-Cayeros, 1997).

La investigación sobre el Ramo 33 se ha enfocado en evaluar sus fondos o sus fórmulas (Consejo Nacional de Evaluación de la Política de Desarrollo Social [CONEVAL], 2011; Sobarzo, Ruiz y García, 2011; Urzúa y Velázquez, 2018; Zepeda, 2011). Además, como parte de sus atribuciones, el CONEVAL evalúa de manera constante los fondos del Ramo 33. Sin embargo, la diferencia entre su presupuesto y el gasto ejercido se ha dejado de lado. Una de las excepciones es la investigación de Guerrero (2011), la cual da cuenta de los determinantes del subejercicio del gasto del Fondo de Aportaciones para la Seguridad Pública (FASP).

Si bien los estudios de México Evalúa (2014 y 2018a) ofrecen algunos datos sobre las diferencias entre el presupuesto y el gasto ejercido, se desconoce cómo tal diferencia se distribuye entre los estados y si hay sesgos partidistas en esa distribución. Por lo anterior, esta investigación analiza qué es lo que sucede con el Ramo 33. Se eligió este ramo porque consiste en recursos etiquetados por el gobierno federal, es decir, ya tienen un destino específico. Por lo tanto, es posible que la distribución de los recursos adicionales (o menores) a los presupuestados tenga un sesgo partidista. Antes de la creación del Ramo 33 , los recursos etiquetados se distribuían de forma discrecional. Con su establecimiento se buscó contar con reglas claras, pero no hay certeza de que esto se haya logrado (Auditoría Superior de la Federación [ASF], 2013; Chiapa y Velázquez, 2011).

Al existir una relación vertical entre el gobierno federal y los estados, y al ser el gobierno federal quien distribuye las trasferencias etiquetadas, es posible que éste destine recursos adicionales a los estados gobernados por la oposición para obtener un beneficio electoral en las próximas contiendas. Con ello también evitaría presiones por parte de la oposición para obtener más recursos. No lo hará en el caso de los estados gobernados por su propio partido, porque ellos están sometidos a la disciplina partidista. Entrar en conflicto sería costoso para ambas partes. En síntesis, la hipótesis de esta investigación es la siguiente: en lo que se refiere al Ramo 33, los estados gobernados por la oposición recibirán más recursos a los presupuestados que aquellos gobernados por el partido del presidente.

Los objetivos de este trabajo son: mostrar información sobre la diferencia entre el presupuesto y el gasto ejercido del Ramo 33 para el periodo 2001-2017; describir cómo el gobierno federal distribuye la magnitud de esa diferencia 
entre los estados; y mediante un análisis cuantitativo, averiguar si la alineación partidista vertical entre el gobierno federal y los estatales incide en esta distribución. ${ }^{5}$

El artículo tiene cinco secciones incluyendo ésta. En la segunda sección se expone la importancia que tienen las trasferencias federales para los ingresos estatales. En la tercera se describen los datos sobre la diferencia entre el presupuesto del Ramo 33 y el gasto ejercido. En la cuarta se expone el argumento teórico, las hipótesis y el análisis cuantitativo. Se cierra con una sección de conclusiones.

\section{Las trasferencias federales y su importancia en los ingresos estatales}

Las trasferencias federales ${ }^{6}$ son recursos que se trasfieren de un orden de gobierno a otro con el objetivo de financiar determinadas necesidades de gasto de los gobiernos receptores (Peña, 2011). Estas trasferencias tienen dos finalidades: reducir los desequilibrios verticales, es decir, la brecha entre las necesidades de gasto y los ingresos de los gobiernos subnacionales; y reducir los desequilibrios horizontales: la diferencia entre ingreso y gasto que existe en los gobiernos subnacionales (OECD, 2016; Peña, 2011). Una forma de clasificar las trasferencias es de acuerdo con su destino. Así, están las trasferencias condicionadas y las no condicionadas. Las primeras son recursos que ya tienen un destino determinado; en contraste, las no condicionadas son de libre disposición por parte del gobierno receptor.

Aunque en México hay cuatro formas para trasferir recursos a los estados y a los municipios, ${ }^{7}$ son dos las más importantes debido a la magnitud que representan con respecto a sus ingresos totales: las aportaciones (Ramo 33), que son trasferencias condicionadas; y las participaciones (Ramo 28), que son trasferencias no condicionadas. Las participaciones (Ramo 28 ) tienen como objetivo específico resarcir a los gobiernos subnacionales y locales "la parte que aportan a la riqueza nacional expresada en los ingresos federales” (Peña, 2011, p. 26). Se componen de diversos fondos que utilizan fórmulas para la distribución de los recursos entre los estados y los municipios. ${ }^{8}$ Por su parte, las aportaciones

5 La alineación partidista vertical se refiere al escenario en el que un mismo partido controla dos o más niveles de gobierno. También se denomina como gobierno unificado vertical.

6 Se habla aquí de trasferencias federales porque es el gobierno federal quien hace tal actividad. Un concepto más general que también se utiliza, independientemente de si se trata de un estado federal o unitario, es el de trasferencias intergubernamentales.

7 Participaciones, aportaciones, excedentes de ingresos federales y convenios de reasignación de recursos (Peña, 2011).

8 Los fondos que componen el Ramo 28 de Participaciones son: Fondo General de Participaciones; Fondo de Fomento Municipal; Fondo de Fiscalización y Recaudación; Fondo de Extracción de Hidrocarburos; Participaciones en el Impuesto Especial sobre Producción y Servicios; Participación por el $0.136 \%$ de la Recaudación Federal Participable; Participación a Municipios por donde se Exportan Hidrocarburos; Incentivos a la Venta Final de Gasolina y Diésel; Tenencia o Uso de Vehículos; Fondo del Impuesto sobre la Renta; Fondo de Compensación sobre Automóviles Nuevos; Fondo de Compensación de REPECOS-Intermedios; y Otros Incentivos Derivados de Convenios de Colaboración (ASF, 2018). No obstante, el Fondo General de Participaciones es el de mayor magnitud: en 2016 representó $72.7 \%$ del total de las participaciones (ASF, 2018). 
(Ramo 33) tienen como objetivo fomentar la equidad entre los estados; para ello, trasfieren los recursos necesarios para que los estados y los municipios cumplan con una serie de competencias que el gobierno federal descentralizó desde la década de 1980. En la actualidad, las aportaciones cuentan con ocho fondos. Más adelante se dan detalles. ${ }^{9}$

Una de las características del federalismo fiscal mexicano es que una parte importante de los ingresos estatales se obtienen de las trasferencias federales (Cabrero, 2013; Instituto Mexicano para la Competitividad [IMCO], 2010; Sobarzo, 2008). En esta sección se exponen datos al respecto para conocer el panorama. En la figura 1 se muestra el porcentaje promedio que las trasferencias federales (aportaciones y participaciones) representan en relación con los ingresos estatales. El promedio general para el periodo 2001-2017 es de $85.8 \%$, es decir, por cada cien pesos de los ingresos estatales, 86 provienen de la federación en forma de aportaciones y participaciones. Como se observa, a lo largo del periodo los valores han oscilado entre un promedio de $81.2 \%$ en 2011 y $88.9 \%$ en 2005.

Figura 1. Porcentaje promedio anual de las trasferencias con respecto a los inqresos estatales, 2001-2017

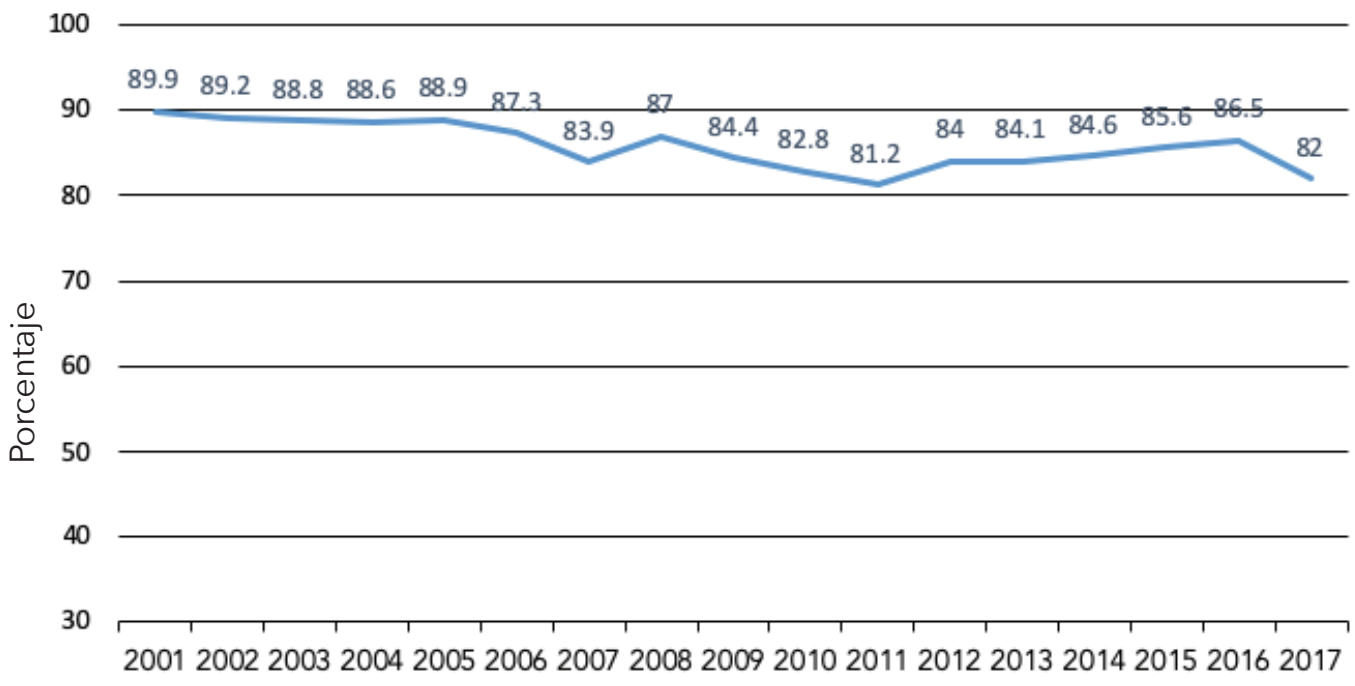

Fuente: elaboración propia con datos del Instituto Nacional de Estadística y Geografía (INEGI, 2019).

A pesar de que los estados obtienen importantes recursos de las trasferencias federales, se pueden detectar diferencias entre ellos. En este sentido, la figura 2 muestra el porcentaje promedio de las trasferencias con respecto a los ingresos por estado. Por un lado, se encuentran aquéllos en los que las trasferencias federales representan, en promedio, alrededor de $90 \%$ de sus ingresos, como Guerrero, Tabasco e Hidalgo. En el extremo opuesto, se ubican Quintana Roo, Estado de México y Nuevo León, donde las trasferencias están entre 72 y $74 \%$.

9 Para un estudio sobre las fórmulas de los fondos del Ramo 28 y 33, véase Urzúa y Velázquez (2018) y Arechederra y Carbajal (2017). 
Figura 2. Porcentaje promedio de las trasferencias con respecto a los ingresos por estado, 2001-2017

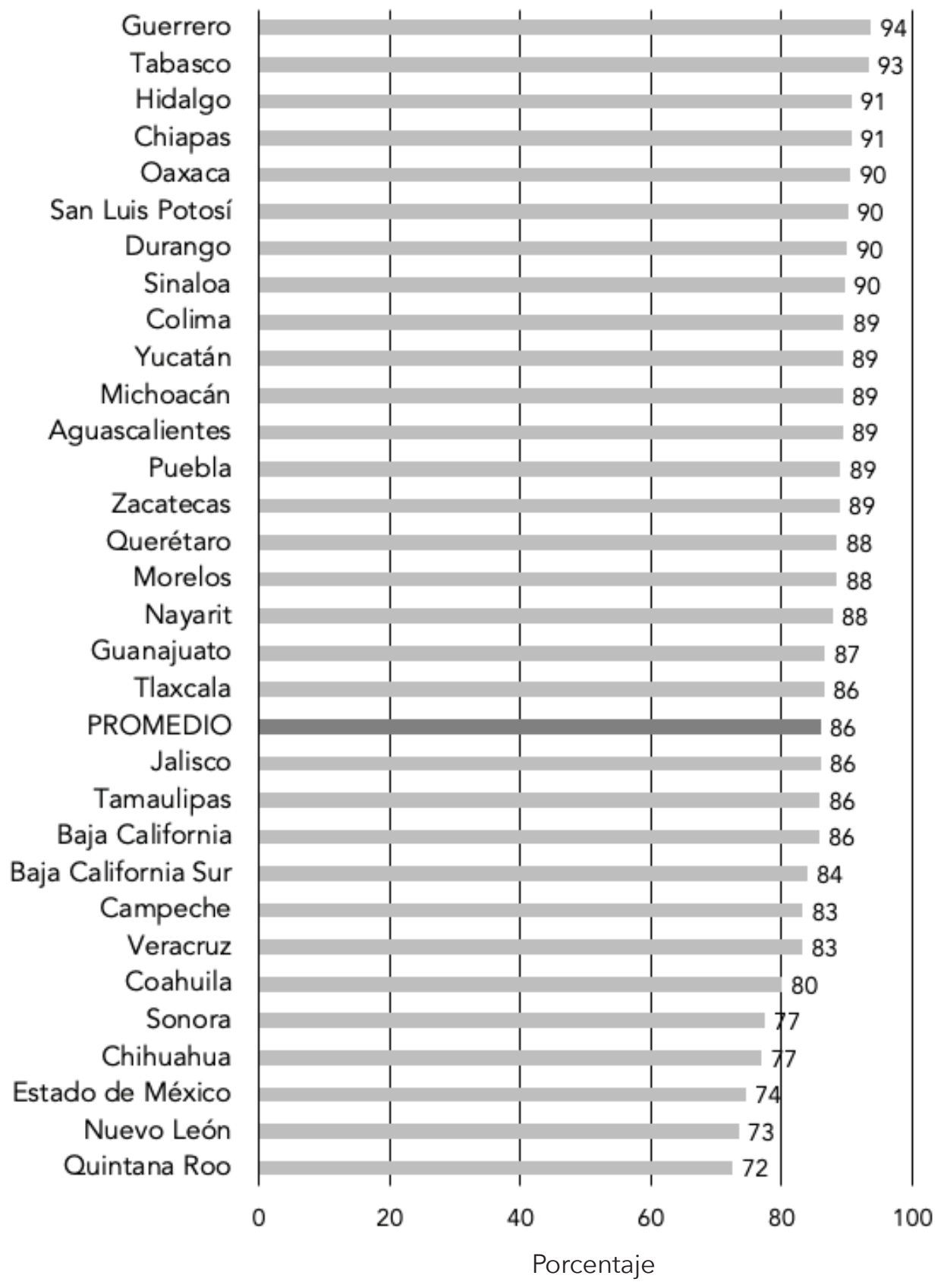

Fuente: elaboración propia con datos del INEGI (2019).

Cuando se analizan por separado las aportaciones (en adelante Ramo 33) y las participaciones (en adelante Ramo 28), también se detectan magnitudes diferentes con respecto a los ingresos estatales, siendo el Ramo 33 el que posee el mayor porcentaje. En todo el periodo, el Ramo 33 representó en promedio $53 \%$ de los ingresos estatales. En la figura 3, se observa que los promedios anua- 


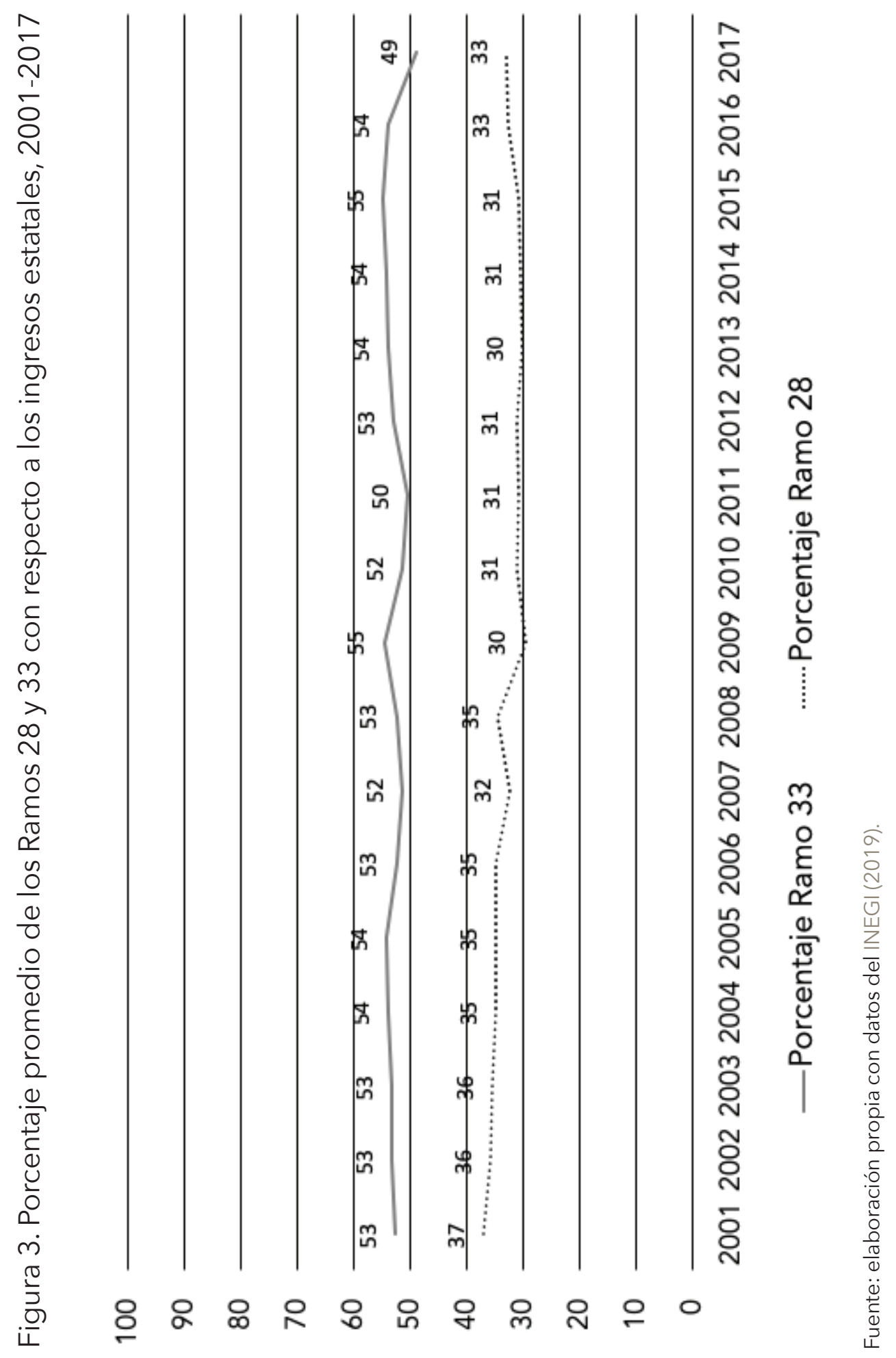


Figura 4. Porcentaje promedio de los ramos con respecto a los ingresos por cada estado, 2001-2017

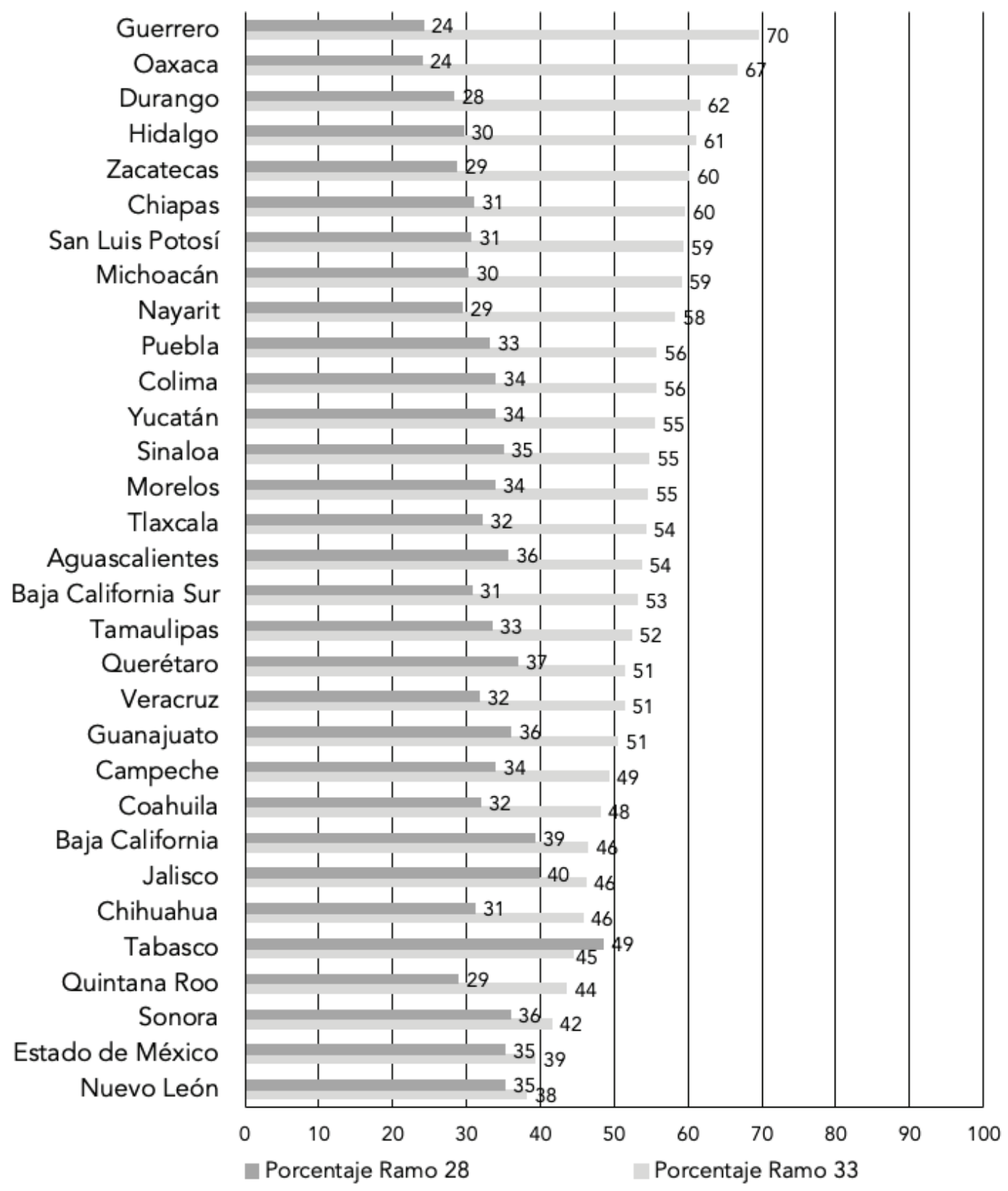

Fuente: elaboración propia con datos del INEGI (2019).

les se han mantenido entre $49 \%$ en 2017 y 55\% en 2015. En el caso del Ramo 28, el promedio para el periodo fue de 33\%, con promedios anuales de $30 \%$ en 2009 y 37\% en 2001.

Para apreciar las diferencias entre los estados, la figura 4 expone los datos por ramo. Lo primero que llama la atención es la relación inversa que existe entre ambos; es decir, a medida que el porcentaje del Ramo 33 aumenta, el por- 
centaje del Ramo 28 disminuye. Lo anterior se podría explicar por los objetivos de cada ramo antes señalados, por las fórmulas de sus fondos y por la capacidad de recaudación de ingresos propios de los estados. Con respecto al Ramo 33, los estados que tienen los porcentajes promedio menores son Nuevo León, Estado de México y Sonora. Por el otro lado, los que obtienen los mayores porcentajes son Guerrero, Oaxaca y Durango. En el caso del Ramo 28, los estados con los menores valores son Oaxaca, Guerrero y Zacatecas. En contraste, aquéllos con los valores mayores son Tabasco, Jalisco y Baja California.

Los datos anteriores destacan la importancia que tienen las trasferencias federales para los ingresos estatales, así como las diferencias que existen entre los estados. En la siguiente sección se analiza la brecha entre el presupuesto del Ramo 33 y el gasto ejercido. De forma complementaria, se muestran los datos del Ramo 28.

\section{Ramo 33: la diferencia entre el presupuesto y el gasto ejercido, 2001-2017}

El Ramo 33 se creó en 1997 como producto de una reforma a la Ley de Coordinación Fiscal (LCF) y comenzó a operar a partir del ejercicio fiscal de 1998. Con esta reforma se añadió el artículo $V$, intitulado "De los fondos de aportaciones federales". Su objetivo fue establecer reglas claras en su distribución, aunque no queda claro en qué medida eso se logró (Chiapa y Velázquez, 2011). Antes de la creación de este ramo, cuando el aspecto político influía, las trasferencias se hacían por medio de convenios entre el gobierno federal y los estados.

En sus inicios, el Ramo 33 contaba sólo con cinco fondos: Fondo de Aportaciones para la Educación Básica y Normal (FAEB), Fondo de Aportaciones para el Fortalecimiento de los Municipios y del Distrito Federal (FAFM), Fondo de Aportaciones Múltiples (FAM), Fondo de Aportaciones para la Infraestructura Social (FAIS) y Fondo de Aportaciones para los Servicios de Salud (FASSA). En 1999 se añadieron dos más: el Fondo de Aportaciones para la Educación Tecnológica y de Adultos (FAETA) y el Fondo de Aportaciones para la Seguridad Pública (FASP) (Chiapa y Velázquez, 2011). El octavo fondo se añadió a finales de 2006, cuando se trasformó el Programa de Apoyo para el Fortalecimiento de las Entidades Federativas (PAFEF) en el Fondo de Aportaciones para el Fortalecimiento de las Entidades Federativas (FAFEF).

En 2007 la LCF se reformó para cambiar las fórmulas de algunos fondos del Ramo 33. Una nueva reforma en 2013 implicó cambios en ciertos fondos, específicamente en su asignación y ejercicio. Además, el FAEB se trasformó en el Fondo de Aportaciones para la Nómina Educativa y Gasto Operativo (FONE), el cual entró en vigor como tal en el año fiscal 2015. En suma, a partir de 2007 el Ramo 33 quedó integrado por ocho fondos, dos de los cuales destinan recursos a los municipios (FORTAMUN y FAIS). En la tabla 1 se exponen los detalles generales de cada uno. ${ }^{10}$

10 Para un análisis sobre las implicaciones de los cambios indicados, véase Urzúa y Velázquez (2018). 
Tabla 1. Fondos del Ramo 33

\begin{tabular}{|c|c|c|}
\hline Fondo* & Destino de los recursos & Antecedentes \\
\hline $\begin{array}{c}\text { Fondo de Aportaciones para } \\
\text { la Nómina Educativa y Gasto } \\
\text { Operativo (FONE) }\end{array}$ & $\begin{array}{c}\text { Educación básica } \\
\text { y normal }\end{array}$ & $\begin{array}{l}\text { Acuerdo Nacional para } \\
\text { la Modernización de la } \\
\text { Educación Básica, FAEB }\end{array}$ \\
\hline $\begin{array}{c}\text { Fondo de Aportaciones } \\
\text { para la Educación Tecnológica } \\
\text { y de Adultos (FAETA) }\end{array}$ & $\begin{array}{c}\text { Educación tecnológica } \\
\text { y educación para } \\
\text { adultos }\end{array}$ & $\begin{array}{l}\text { Convenios de } \\
\text { coordinación } \\
\text { CONALEP e INEA }\end{array}$ \\
\hline $\begin{array}{c}\text { Fondo de Aportaciones para el } \\
\text { Fortalecimiento de las Entidades } \\
\text { Federativas (FAFEF) }\end{array}$ & $\begin{array}{l}\text { Infraestructura } \\
\text { y deuda pública }\end{array}$ & PAFEF \\
\hline $\begin{array}{c}\text { Fondo de Aportaciones para } \\
\text { el Fortalecimiento de los } \\
\text { Municipios y de las } \\
\text { Demarcaciones Territoriales del } \\
\text { Distrito Federal (FORTAMUN) }\end{array}$ & $\begin{array}{c}\text { Obligaciones } \\
\text { financieras } \\
\text { y desarrollo municipal }\end{array}$ & Ramo 26 \\
\hline $\begin{array}{l}\text { Fondo de Aportaciones para la } \\
\text { Infraestructura Social (FAIS) }\end{array}$ & $\begin{array}{l}\text { Infraestructura } \\
\text { social básica }\end{array}$ & $\begin{array}{l}\text { Recursos del Ramo 26; } \\
\text { Programa Nacional } \\
\text { de Solidaridad }\end{array}$ \\
\hline $\begin{array}{l}\text { Fondo de Aportaciones Múltiples } \\
\text { (FAM) }\end{array}$ & $\begin{array}{l}\text { Desayunos escolares } \\
\text { e infraestructura física }\end{array}$ & $\begin{array}{c}\text { DIF: desayunosescolares. } \\
\text { CAPCE: infraestructura } \\
\text { educativa }\end{array}$ \\
\hline $\begin{array}{l}\text { Fondo de Aportaciones para la } \\
\text { Seguridad Pública de los Estados } \\
\text { y del Distrito Federal (FASP) }\end{array}$ & Seguridad pública & $\begin{array}{l}\text { Convenio de } \\
\text { Coordinación en } \\
\text { Materia de Seguridad } \\
\text { Pública }\end{array}$ \\
\hline $\begin{array}{c}\text { Fondo de Aportaciones para los } \\
\text { Servicios de Salud (FASSA) }\end{array}$ & Servicios de salud & $\begin{array}{l}\text { Acuerdo Nacional para } \\
\text { la Descentralización } \\
\text { de los Servicios de Salud }\end{array}$ \\
\hline
\end{tabular}

*Denominación establecida en el capítulo V de la Ley de Coordinación Fiscal vigente en febrero de 2019.

Fuente: Ley de Coordinación Fiscal (1978) y Chiapa y Velázquez (2011).

Como se destacó en la introducción, varios estudios han mostrado que el gobierno federal ejerce por lo general un gasto mayor al que se presupuestó, de manera específica, en la forma de sobreejercicios (Diaz-Cayeros y Magaloni, 1998; México Evalúa, 2014, 2018a, 2018b; Núñez, 2017; Ugalde, 2018). Así mismo, se ha evidenciado que en rubros específicos, como los Ramos Generales, se observa un comportamiento similar (México Evalúa, 2014, 2018a). En esta sección se analiza la diferencia entre el gasto presupuestado y el gasto ejercido del Ramo 33 durante el periodo 2001-2017, y cómo se distribuye entre los estados. Para medir esta diferencia, se utiliza la siguiente fórmula: ${ }^{11}$

11 Un indicador similar es utilizado por PEFA (2016) y, como se indicó, por la ONU (2017) dentro de los Objetivos de Desarrollo Sostenible. 


$$
G N E=\frac{(G E-G P)}{G P} * 100
$$

Donde GNE es el gasto neto ejercido del Ramo 33; GE es el gasto ejercido y GP es el gasto presupuestado. Los datos del GE y del GP se obtuvieron de la Cuenta Pública del gobierno federal. Como se observa, a partir de la diferencia entre ambos valores se obtiene su porcentaje con respecto a los recursos presupuestados. Un valor positivo indica que existe un sobreejercicio y un valor negativo indica un subejercicio. De manera complementaria, también se exponen los datos del GNE para el Ramo 28 (participaciones).

Figura 5. Gasto neto ejercido promedio anual del Ramo 33 y del Ramo 28, 2001-2017

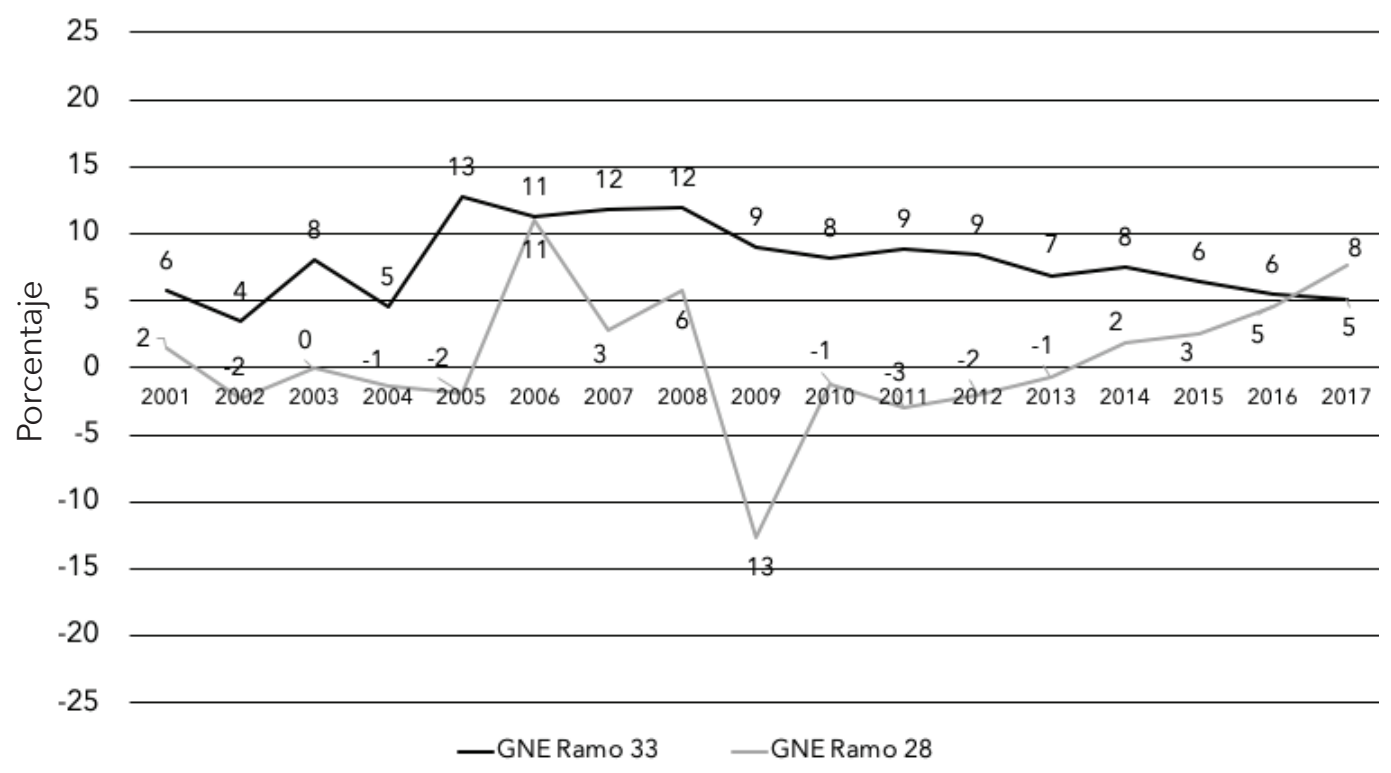

Fuente: elaboración propia con datos de la Secretaría de Hacienda y Crédito Público (SHCP) (2019).

En la figura 5 se muestran los valores promedio anuales del GNE para el Ramo 33 y el Ramo 28. Se aprecia que el GNE del Ramo 33 presenta valores positivos en todo el periodo, es decir, sobreejercicios, con promedios anuales entre $4 \%$ en 2002 y $13 \%$ en 2005 . Desde ese año, el GNE se ha reducido de forma constante. Por su parte, el GNE del Ramo 28 tiene un comportamiento diferente, ya que presentó valores positivos y negativos. Además, se observa que la crisis económica mundial impactó con más fuerza sus valores en 2009. A partir de 2010 hay una relación inversa entre ambos Ramos: el GNE del Ramo 33 disminuye mientras que el del Ramo 28 aumenta. 
Figura 6. Gasto neto ejercido promedio del Ramo 33 y Ramo 28 por estado, 2001-2017

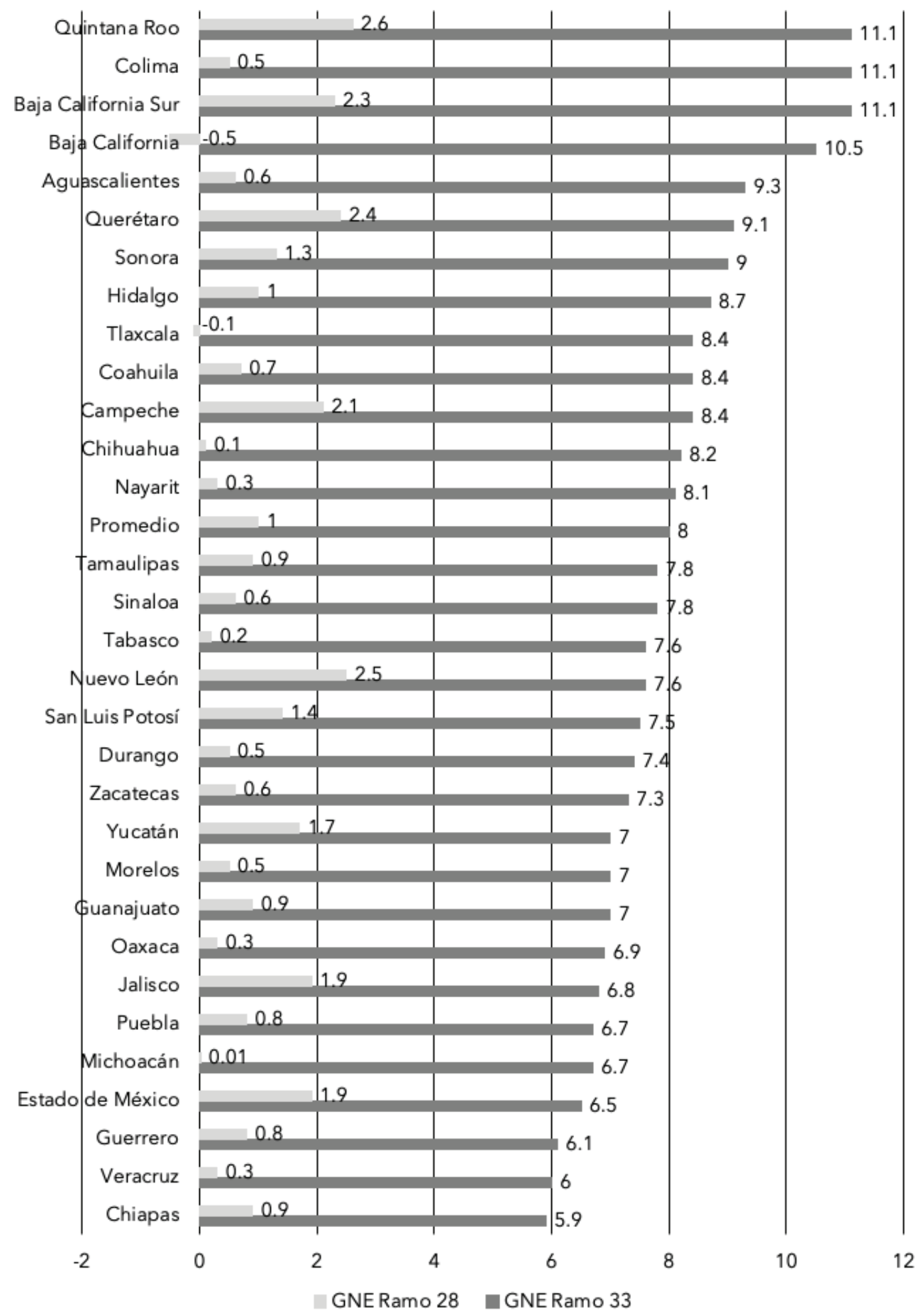

Fuente: elaboración propia con datos de la SHCP (2019). 
En la figura 6 se expone cómo el GNE se distribuye entre los estados. En primer lugar, el promedio general del GNE para el Ramo 33 es de 8\%. En un extremo se ubican Quintana Roo, Colima y Baja California Sur, con 11.1\%. En el lado opuesto, están Chiapas, Veracruz y Guerrero, con 5.9, 6, y 6.1\%, respectivamente. Los valores del GNE del Ramo 28 son menores: el promedio general es de 1\%. Dos estados recibieron menos de lo presupuestado: Baja California, con un promedio de $0.5 \%$ y Tlaxcala, con un promedio de $0.1 \%$. Por el otro lado, Quintana Roo, Nuevo León y Querétaro tuvieron un GNE promedio de 2.6, 2.5 y $2.4 \%$, respectivamente.

Además, se registran diferencias longitudinales en cada estado. Las figuras 7 y 8 muestran el comportamiento del GNE de los ramos 33 y 28 . Una vez más se observa que en el caso del Ramo 33 los sobreejercicios son los que predominan la mayor parte del tiempo. Por supuesto, cada estado tiene comportamientos diferentes. Por un lado, están aquéllos con más dispersión. Por ejemplo, en Campeche, los valores tuvieron un mínimo de 3.3\% y un máximo de 19.9\%; en Coahuila los valores oscilaron entre 0.3 y $20.7 \%$; y en Tamaulipas, entre 0.2 y 14.6\%. En contraste, estados como Chiapas, Veracruz, Michoacán y Nuevo León presentaron menores variaciones. En lo que respecta al GNE del Ramo 28, los cambios son más pronunciados en la mayoría de los estados. Cabe destacar que $42.5 \%$ de estas observaciones presentaron subejercicios entre 0.1 y $16.5 \%$.

Figura 7. Gasto neto ejercido del Ramo 33 y Ramo 28 por estado, 2001-2017

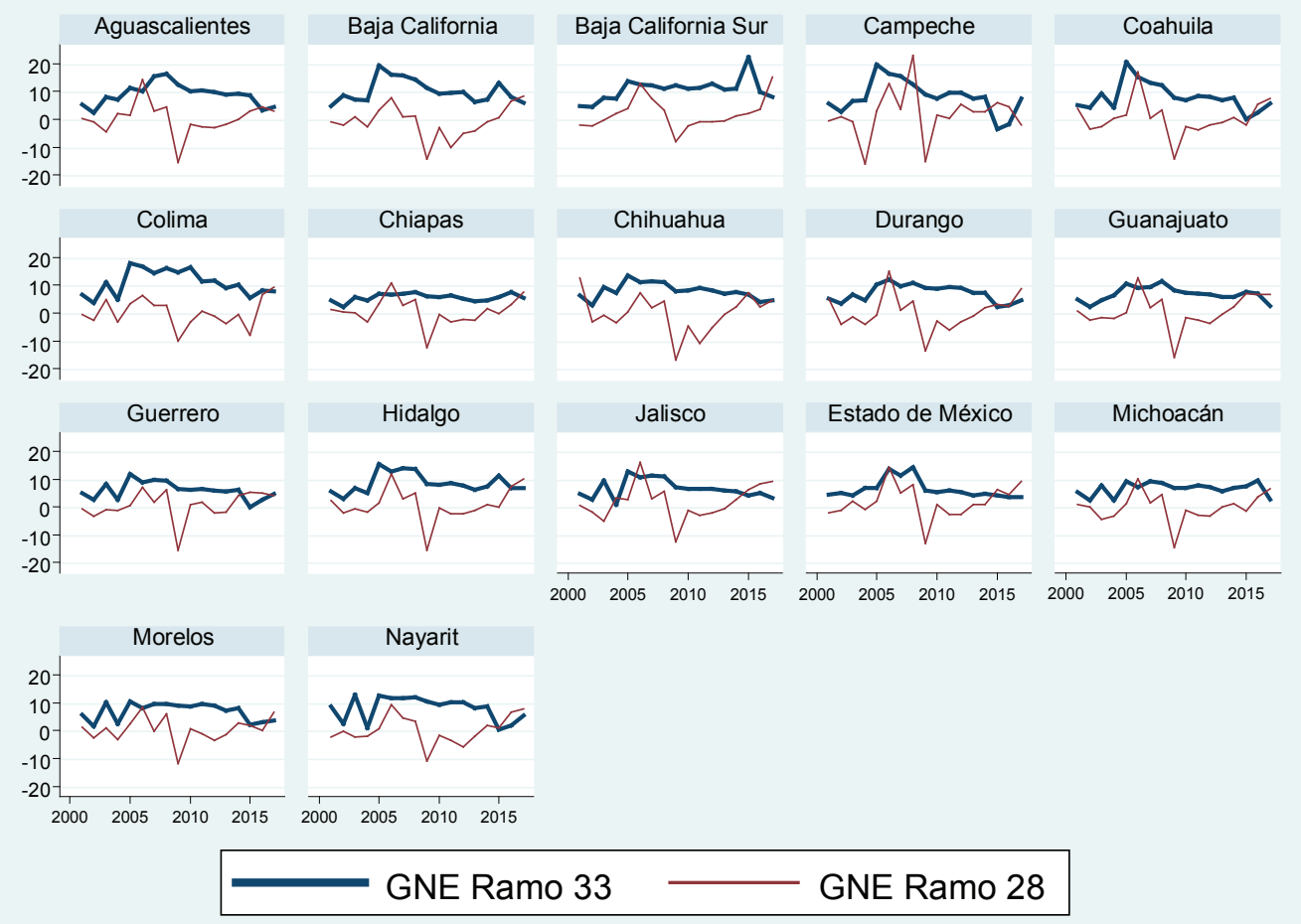

Fuente: elaboración propia con datos de la SHCP (2019). 
Figura 8. Gasto neto ejercido del Ramo 33 y Ramo 28 por estado, 2001-2017 (continuación)

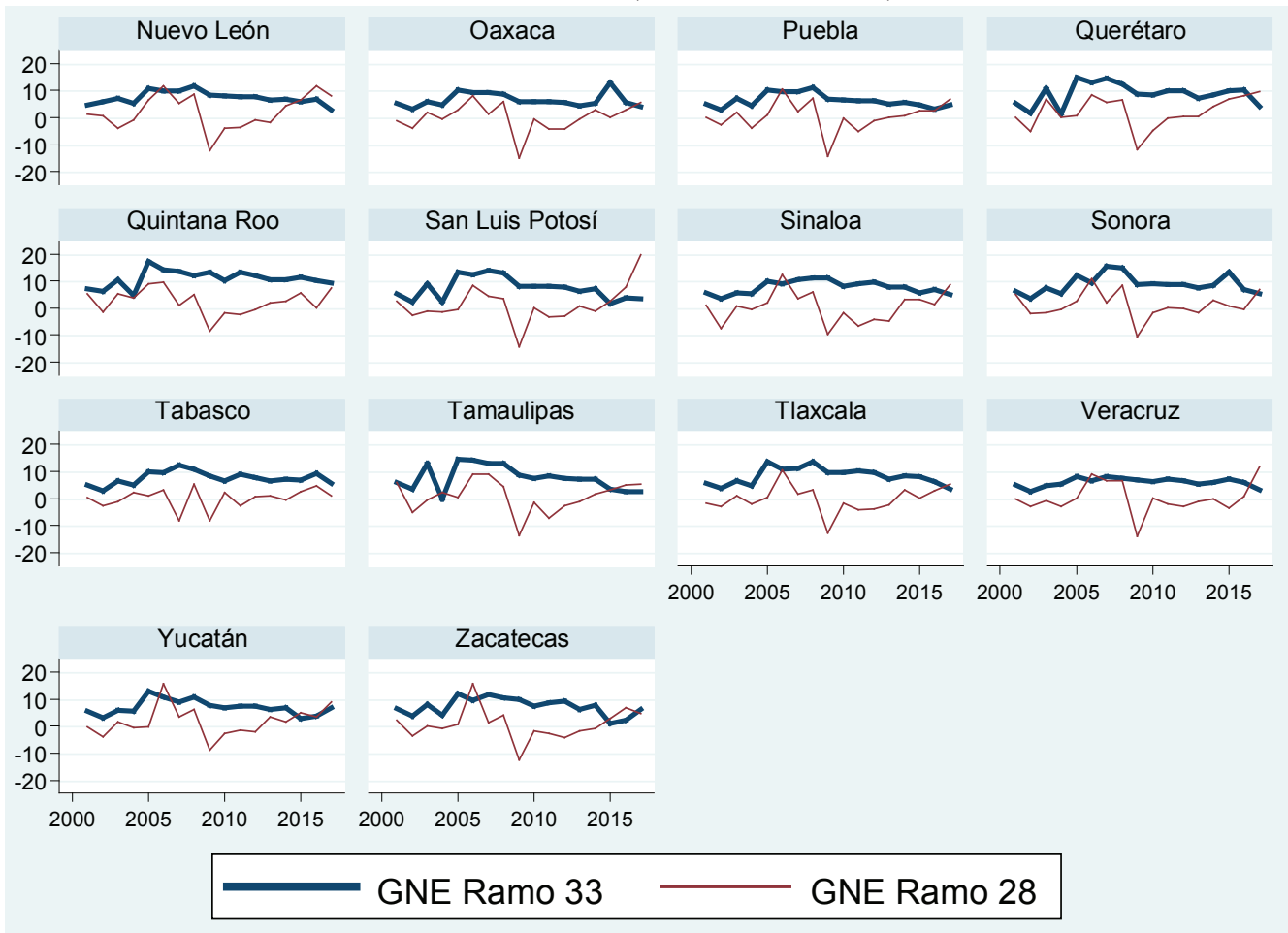

Fuente: elaboración propia con datos de la SHCP (2019).

Los datos anteriores resultan interesantes porque muestran la brecha entre lo planeado y lo ejercido. En el caso del Ramo 33, la diferencia se presenta por lo general en la forma de sobreejercicios, mientras que en el caso del Ramo 28 hay sobre y subejercicios. En la siguiente sección se exponen el argumento teórico y la hipótesis respectiva para explicar este comportamiento.

\section{Argumento teórico e hipótesis}

Una de las características de los sistemas federales es que existen, al menos, dos niveles de gobierno con autonomía constitucional. Esta característica es la que les permite actuar de manera independiente, por lo que el conflicto entre los niveles de gobierno es latente. Al respecto se ha argumentado que los partidos políticos son la fuente de este conflicto: puesto que cada nivel de gobierno es electo por el voto popular, existe la posibilidad de que partidos políticos diferentes estén al mando de cada nivel (Riker y Schaps, 1957). En una situación así, el partido A en el gobierno federal puede actuar en contra de los gobiernos subnacionales del partido $B$, y viceversa. Por supuesto, también existe la posibi- 
lidad de que el mismo partido pueda tener el control del gobierno federal y de los gobiernos estatales. En semejante situación, las probabilidades de conflicto disminuyen y es la cooperación lo que prevalece.

Varios autores han retomado la idea de que los partidos políticos son la causa del conflicto o de la cooperación entre los niveles de gobierno (Garman, Haggard y Willis, 2001; Jones, Sanguinetti y Tommasi, 2000; Rodden, 2001; Rodden y Wibbels, 2002). No obstante, algunos han complementado el argumento. En este sentido, Garman et al. (2001) parten de la idea de que cada nivel de gobierno tiene prioridades diferentes. En el tema de la descentralización fiscal, la preferencia del gobierno federal es controlar los recursos que trasfiere a los estados. De manera específica, un control centralizado le permitirá igualar la distribución de bienes y servicios en todo el país en función de sus necesidades, así como distribuir recursos para fines exclusivamente políticos: ganar las elecciones y mantener las coaliciones legislativas. En términos concretos, en el caso de que el presidente decida trasferir responsabilidades a los estados, evitará darles los recursos necesarios para desempeñarlas. Al contrario, preferirá que los impuestos locales financien tales responsabilidades y no las trasferencias federales. En escenarios en los que las trasferencias ya existen, el presidente buscará controlar su uso, lo cual se puede lograr por medio de los recursos etiquetados. En el caso extremo, intentará controlar todos los recursos fiscales de forma discrecional.

Por su parte, los gobernadores prefieren recibir las trasferencias del gobierno federal en vez de aumentar su propia recaudación impositiva. Por supuesto, también puede existir el caso extremo en el que los gobernadores quieren el control absoluto de tales recursos sin que exista una responsabilidad sobre su ejercicio. En concreto, los gobiernos estatales se concentran en que haya certeza en la obtención de las trasferencias y en las condiciones para acceder a ellas.

Retomando la idea de Riker y Schaps (1957), para Garman et al. (2001) la relación partidista entre el gobierno federal y los gobiernos estatales pueden afectar las preferencias señaladas. En un contexto de gobierno dividido vertical, es decir, cuando el presidente y los gobernadores son de partidos diferentes, la divergencia entre las preferencias será más pronunciada. Aquí, el gobierno federal podría trasferir algunas funciones a los gobiernos subnacionales, pero se negará a dar recursos a sus oponentes. Por su parte, los gobernadores buscarán atar las manos del gobierno central por medio del establecimiento de fórmulas fijas en la distribución de los recursos.

En cambio, con un gobierno unificado vertical, es decir, cuando el mismo partido controla ambos niveles de gobierno, la diferencia entre sus preferencias podría ser menor. Esto es posible gracias a ciertas características internas de los partidos políticos. Si el partido político es muy jerárquico, el presidente determina las carreras de los gobernadores a través del control de las nominaciones, el financiamiento de campañas y la designación en cargos públicos. Por lo tanto, se espera que las preferencias de los gobernadores estén subordinadas a las del presidente, lo que podría implicar una mayor centralización en la toma de decisiones. Si el partido es menos jerárquico, se espera que las preferencias 
de los gobernadores prevalezcan sobre las del presidente, lo cual implicaría una mayor descentralización. ${ }^{12}$

En su argumento, Rodden (2001) también retoma la idea de Riker y Schaps (1957), pero hace hincapié en el mecanismo que permite la cooperación entre los niveles de gobierno en contextos de gobierno unificado vertical, a saber, las externalidades electorales. Puesto que en un sistema federal el mismo partido puede gobernar dos niveles de gobierno, el desempeño que tiene en un nivel puede afectar de modo positivo o negativo los resultados electorales en otro nivel. En otros términos, los votantes pueden ver en las elecciones estatales una especie de referéndum sobre el desempeño del partido a escala nacional. Cuando el gobierno federal tiene un mal desempeño, se castiga al partido tanto a escala nacional como subnacional. En caso contrario, los electores lo premiarán eligiéndolo por un periodo más. Por ejemplo, si la estabilidad macroeconómica es la clave para el éxito del partido nacional, entonces los gobiernos estatales del mismo partido del presidente tienen incentivos para cooperar y lograr tal o cual objetivo (Rodden y Wibbels, 2002). Una actitud contraria podría ser contraproducente para el futuro político del partido, ya que afectaría las posibilidades para maximizar los votos en las próximas elecciones y lograr la reelección. Por lo tanto, la cooperación entre niveles de gobierno que pertenecen al mismo partido es posible debido a estas externalidades electorales. En contraste, los estados gobernados por la oposición se afectan en el sentido inverso: si el gobierno federal fracasa, ellos podrán beneficiarse en términos electorales.

Igualmente, se puede mencionar la propuesta analítica de Benton (2019), que retoma las ideas anteriores y establece que los mecanismos de cooperación detrás de una alineación partidista vertical son el liderazgo partidista y la reputación del partido. El primer mecanismo existe cuando el líder partidista controla el acceso a las oportunidades políticas dentro de sus esferas territoriales de autoridad. En consecuencia, los políticos subnacionales buscan calmar a su líder para asegurar el acceso a tales puestos de elección popular o de designación. El segundo mecanismo existe cuando el desempeño macroeconómico del país puede afectar tanto a los funcionarios nacionales como a los subnacionales. Un desempeño económico óptimo fortalece la reputación y el apoyo electoral del gobierno nacional y aumenta las oportunidades políticas disponibles para los copartidarios subnacionales. En contraste, un pobre desempeño macroeconómico debilita la reputación y el apoyo electoral del gobierno nacional, lo cual reduce las oportunidades políticas disponibles para los copartidarios subnacionales (Benton, 2019).

En síntesis, en la relación entre los niveles de gobierno en un sistema federal, el partido político es un instrumento que puede permitir la coordinación o el conflicto. Habrá más posibilidades de cooperación cuando ambos niveles estén controlados por el mismo partido; en contraparte, habrá más probabilidades de conflicto cuando cada nivel de gobierno esté en manos de partidos políticos diferentes.

12 Recientemente se ha mostrado que la reacción de los gobernadores depende del tipo de tema. En el caso mexicano, se ha observado que los gobernadores aceptan la recentralización en el tema administrativo, pero la rechazan en el tema político (Armesto y Olmeda, 2017). 
¿Qué muestra la evidencia sobre los efectos de la alineación partidista vertical? ¿Hay una diferencia entre los gobiernos divididos verticales y los gobiernos unificados verticales? En general, las investigaciones internacionales muestran que sí importa la alineación partidista en diversos temas. Se ha demostrado que cuando un mismo partido gobierna el nivel federal y el nivel estatal, el gasto de los estados es menor (Jones et al., 2000), hay mayores grados de centralización fiscal (Garman et al., 2001), el superávit es más alto y la inflación es más baja (Rodden y Wibbels, 2002), los acuerdos se llevan de mejor manera (Esselment, 2012), hay menos disputas entre niveles de gobierno (Bulman-Pozen, 2014; Read, 2016) y el gobierno federal delega más responsabilidades en los estados (Krause y Bowman, 2005).

En el caso mexicano, los estudios muestran resultados contrastantes. Algunos han demostrado que la alineación partidista tiene un efecto sobre las trasferencias federales (Flamand, 2006; México Evalúa, 2018a)en particular, si las elecciones competitivas y el gobierno dividido verticalmente, como elementos de los procesos de democratización, han cambiado las relaciones fiscales entre los estados y el gobierno federal. El artículo emplea modelos de datos de panel de efectos fijos con errores estándar corregidos para estimar los efectos de estas variables en la asignación de fondos federales no condicionados (participaciones. ${ }^{13}$ Pero otros no han hallado los efectos en temas como el gasto público (Velázquez, 2006) la dependencia financiera (Ibarra, 2013), los recursos discrecionales (Busmail y Miño, 2016) y la carga de la deuda (Ibarra y Santos, 2018).

Ya que México es un Estado federal, cada nivel de gobierno puede estar en manos de partidos políticos diferentes. Por lo tanto, se espera que haya una relación distinta entre una situación en la que un mismo partido gobierna el nivel federal y el estatal (gobierno unificado vertical) y otra en la que suceda lo contrario (gobierno dividido vertical). Esta investigación busca determinar si el gobierno federal distribuye de forma sesgada el GNE. En el caso del Ramo 33, al tratarse de recursos etiquetados, se espera que el gobierno federal dé un trato "preferencial" a los estados gobernados por la oposición, porque buscará influir en esos territorios para obtener una ganancia electoral en las próximas contiendas (tanto nacionales como en ese estado) y para evitar presiones de la oposición. Aunque Garman et al. (2001) argumentan que el gobierno federal dará menos recursos a los estados de la oposición, el Ramo 33 consiste en recursos etiquetados; en consecuencia, el gobierno federal tiene un mayor control sobre ellos en comparación con los recursos no etiquetados. Por lo tanto, la hipótesis es: los estados gobernados por la oposición tendrán un mayor GNE del Ramo 33 que los gobernados por el partido del presidente.

13 Cabe decir que la investigación de Flamand se enfoca en los últimos años de la década de 1990. Incluso en el tema de la violencia, con datos para 2006-2012, se comprobó que la violencia criminal a escala municipal fue mayor cuando el municipio y el estado fueron gobernados por partidos diferentes al del presidente, y mucho mayor en los estados gobernados por el Partido de la Revolución Democrática (PRD) (Trejo y Ley, 2016).. 
De manera exploratoria, se tiene en cuenta qué sucede con el GNE del Ramo 28. Al ser recursos no etiquetados, el gobierno federal tratará de dar menos recursos adicionales, ya que los estados tienen plena autonomía sobre su destino. Como se mostró anteriormente, el GNE del Ramo 28 es menor que el del Ramo 33. Pero ¿hay alguna diferencia entre los gobiernos estatales de su partido y los de la oposición? En este tipo de recursos sí se aplicaría el argumento de Garman, Haggard y Willis. La hipótesis es: los estados de oposición tendrán un menor GNE del Ramo 28 que aquellos gobernados por el partido del presidente.

Ya que se ha argumentado que los gobiernos manipulan la política económica en contextos electorales (Nordhaus, 1975), en el siguiente análisis se controla por esta variable. A escala internacional, varias investigaciones han demostrado que existe tal efecto (Bove, Efthyvoulou y Navas, 2017; Katsimi y Sarantides, 2012; Shi y Svensson, 2006; Vergne, 2009). En México también se ha observado que los años electorales tienen un impacto, aunque depende del tipo de gasto analizado (Gámez e Ibarra-Yúnez, 2009; Ramírez y Erquizio, 2012) o del tipo de elecciones (Argáez, 2016). Para la presente investigación, se espera que en años electorales para gobernador el GNE del Ramo 33 sea mayor que en años no electorales. Por otro lado, el GNE del Ramo 28 será menor en años electorales.

\section{Análisis y resultados}

Para comprobar la hipótesis propuesta se cuenta con una base de datos de tipo panel con información para los 31 estados durante el periodo 2001-2017, la cual arroja un total de 527 observaciones. ${ }^{14}$ En la tabla 2 se ofrece la estadística descriptiva de las variables que se van a utilizar para explicar el GNE. Como se indicó, el promedio general del GNE del Ramo 33 es de 8\%, con un mínimo de $3.3 \%$ y un máximo de $22.6 \%$. El GNE promedio del Ramo 28 es de $0.97 \%$, con un mínimo de $16.5 \%$ y un máximo de $23.2 \%$. Con respecto a la alineación partidista vertical, $63 \%$ de las observaciones tuvo gobierno dividido vertical, mientras que $37 \%$ se ubicó en la situación opuesta. En el caso del calendario electoral, 35\% de las observaciones corresponde a los años electorales (año previo a la elección y año de la elección) y $65 \%$ restante a los años no electorales (el resto de los años). Además, al tratarse de recursos federales que en teoría tienen un objetivo compensatorio (Peña, 2011), es decir, dar más recursos a los estados más marginados, se controla por el índice de marginación elaborado por el Consejo Nacional de Población (2019a). Se utilizó el índice trasformado en una escala de 0 a 100, en la cual un mayor valor significa un mayor nivel de marginación. ${ }^{15}$

14 Se hizo el corte en 2017 debido a la disponibilidad de información.

15 Para trasformar los valores se usó la siguiente fórmula: $\left(\frac{n \text {-min }}{\max \text {-min }}\right) * 100$. Donde al valor del índice del estado $n$ en el año $t$ se le resta el valor mínimo $(\min )$ del índice del año t y se divide entre la diferencia del valor máximo (max) y mínimo del índice del año t. El Consejo Nacional de Población (CONAPO) ha calculado índices para 2000, 2005, 2010 y 2015. Los valores intermedios se obtuvieron mediante interpolación. Los valores de 2016 y 2017 se obtuvieron mediante extrapolación, tomando como referencia los valores de 2010 y 2015. 
Tabla 2. Estadística descriptiva

\begin{tabular}{|c|c|c|c|c|c|}
\hline Variable & Media & $\begin{array}{c}\text { Desviación } \\
\text { estándar }\end{array}$ & Mínimo & Máximo & Observaciones \\
\hline GNE Ramo 33 & 8 & 3.6 & 3.3 & 22.6 & 527 \\
\hline GNE Ramo 28 & 0.97 & 5.7 & 16.5 & 23.2 & 527 \\
\hline Alineación partidista vertical & 0.63 & 0.49 & 0 & 1 & 527 \\
\hline Gobierno dividido vertical & & & & & $\begin{array}{c}330 \\
(63 \%)\end{array}$ \\
\hline Gobierno unificado vertical $^{*}$ & & & & & $\begin{array}{c}297 \\
(37 \%)\end{array}$ \\
\hline Calendario electoral & 0.35 & 0.48 & 0 & 1 & 527 \\
\hline Años electorales & & & & & $\begin{array}{c}184 \\
(35 \%)\end{array}$ \\
\hline Años no electorales & & & & & $\begin{array}{c}343 \\
(65 \%)\end{array}$ \\
\hline Índice de marginación & 36.9 & 25.1 & 0 & 100 & 527 \\
\hline Población (millones) & 3.3 & 2.8 & .45 & 16.9 & 527 \\
\hline $\begin{array}{l}\text { PIB estatal } \\
\text { (millones de pesos) }^{\star \star}\end{array}$ & 388792.1 & 295534 & 67732.9 & 1549795 & 527 \\
\hline
\end{tabular}

${ }^{*}$ En los casos de los gobiernos estatales con alianzas entre el Partido Acción Nacional (PAN) y el PRD, se hizo una reclasificación para ubicarlos sólo en un partido, según el partido que haya postulado primero al candidato de la alianza electoral o manifestado primero su apoyo. Un procedimiento similar fue utilizado previamente por Trejo y Ley (2016). Ya que el Partido Verde Ecologista de México (PVEM) gobernó un solo estado (Chiapas, 2012-2018) y ganó en alianza con el Partido Revolucionario Institucional (PRI), se contabilizó en el grupo de este partido.

${ }^{*}$ Cálculos realizados con información del INEGI (2019) y del CONAPO (2019b). Los valores están en precios de 2013.

Fuente: elaboración propia con datos del INEGI (2019), SHCP (2019), CONAPO (2019a) y los Organismos Públicos Locales Electorales (OPLES) (2019).

Después de aplicar la prueba de Hausman, se determinó utilizar efectos fijos, pero estableciendo un control por efectos temporales. Además, puesto que se detectaron problemas de heterocedasticidad, se utilizaron estimadores con errores estándar corregidos para panel. El modelo es:

gne33 ${ }_{i, t}=B_{1} g d v_{i, t}+B_{2} e l e c{ }_{i, t}+B_{3}$ marg $_{i, t}+B_{4} l p i b+B_{5} l p o b+E_{i}+T_{t}+\varepsilon$

Donde gne33 es el GNE del Ramo 33, expresado en porcentaje; gdv es una variable dicotómica para la alineación partidista vertical (gobierno dividido vertical=1; gobierno unificado vertical $=0) ;{ }^{16}$ y elec es una variable dicotómica para los años electorales (años electorales $=1$; años no electorales $=0$ ). Se controlan por el índice de marginación (marg), el producto interno bruto estatal (lpib),

16 No se consideró la variable sobre etiqueta del partido político en el gobierno estatal, ya que comparten observaciones en algunas categorías con la variable de la alineación partidista vertical. Por ejemplo, durante los gobiernos federales panistas (2001-2012), la categoría de gobierno unificado vertical integra a todos los gobiernos estatales con etiqueta panista. Lo mismo se aplica para el gobierno federal priista (2013-2018). 
la población (lpob), el efecto de los estados $(E)$ y de los años $(T)$. En el caso del modelo para el Ramo 28, también se usaron efectos fijos. No hubo problemas de heterocedasticidad, pero sí efectos temporales. Los resultados se exponen en la tabla 3.

Tabla 3. Resultados del gasto neto ejercido del Ramo 33, 2001-2017

\begin{tabular}{|l|c|c|}
\hline & $\begin{array}{c}\text { M1 } \\
\text { (GNE Ramo 33) }\end{array}$ & $\begin{array}{c}\text { M1 } \\
\text { (GNE Ramo 28) }\end{array}$ \\
\hline Gobierno dividido vertical & 0.237 & 0.483 \\
& $(0.218)$ & $(0.319)$ \\
\hline Años electorales & 0.049 & 0.298 \\
& $(0.192)$ & $(0.27)$ \\
\hline Índice de marginación & $0.082^{*}$ & $0.135^{* *}$ \\
& $(0.046)$ & $(0.064)$ \\
\hline Población & $11.15^{* \star}$ & 3.796 \\
(logaritmo natural) & $(3.62)$ & $(4.35)$ \\
\hline PIB estatal & $3.14^{*}$ & 1.491 \\
(logaritmo natural) & $(1.737)$ & $(1.609)$ \\
\hline$R^{2}$ & 0.7232 & 0.4590 \\
\hline$R^{2}$ (entre) & & 0.0477 \\
\hline$R^{2}$ (dentro) & & 0.7920 \\
\hline Observaciones & 527 & 527 \\
\hline
\end{tabular}

${ }^{*} \mathrm{p}<=0.1$

${ }^{* *} p<=0.05$

${ }^{* * *} p<=0.01$

Errores estándar entre paréntesis.

Fuente: elaboración propia con datos de salida del modelo.

Para el GNE del Ramo 33, se observa que el efecto del gobierno dividido tiene el signo esperado, pero no resultó significativo en términos estadísticos. Esto quiere decir que en la distribución de recursos adicionales del Ramo 33 (GNE) no hay una influencia de tipo partidista. En otras palabras, estos recursos etiquetados no se están distribuyendo de manera discrecional o con un sesgo partidista. Los años electorales tampoco fueron significativos. A pesar de que esto podría ser una buena noticia, los resultados de las otras variables llaman la atención. En el caso del índice de marginación, se aprecia una relación paradójica, porque mientras mayor sea la marginación, menor es la magnitud del GNE, es decir, se destinan menos recursos adicionales. ${ }^{17}$

17 Esto no quiere decir que los montos presupuestados o ejercidos, por separado, también sean afectados. No hay que perder de vista que nuestra investigación se concentra en la diferencia entre ellos. 
En el caso del PIB estatal, la relación también va en contra del sentido común, ya que reciben más GNE los estados con más PIB. Si el Ramo 33 tiene un objetivo igualitario entre los estados, los resultados de estas dos variables indican que está haciendo justamente lo contrario. Por lo tanto, es preciso revisar y replantear las fórmulas de distribución de los fondos que componen el Ramo 33. ${ }^{18}$

En relación con el GNE del Ramo 28, el signo es el opuesto al esperado, aunque no es significativo en términos estadísticos. Los años electorales tampoco resultaron significativos. De nuevo, el índice de marginación tuvo una relación inversa y significativa: a mayor marginación menor GNE. Las variables de control de la población y el PIB estatal no fueron significativas.

Los resultados sobre el impacto de la alineación partidista vertical contrastan con otros estudios, como el de México Evalúa (2018a), en el que se detectó una distribución sesgada de los recursos del Ramo $23 .{ }^{19}$ También existe un contraste con los resultados de Flamand (2006), los cuales muestran que los gobiernos en manos de la oposición recibieron más trasferencias federales (participaciones y aportaciones). Pero su estudio analizó el periodo 1995-1999 y no se enfocó en la diferencia entre el presupuesto y el gasto ejercido, sino en el monto total. En cambio, nuestros resultados coinciden con los hallazgos de Velázquez (2006), Ibarra (2013) y Busmail y Miño (2016), quienes tampoco detectaron un impacto de la alineación partidista vertical.

\section{Conclusiones}

Este artículo mostró que, en primer lugar, existe una diferencia entre el monto presupuestado y el monto ejercido del Ramo 33, específicamente en la forma de sobreejercicios. Además, su distribución entre los estados tuvo magnitudes diferentes. Esto coincide con los resultados de las investigaciones previas enfocadas en el PEF y en otros rubros del gasto. En relación con el Ramo 28, se observó que el GNE promedio es menor, pero las variaciones son mayores.

En segundo lugar, al tratar de explicar estas diferencias, los resultados del análisis cuantitativo mostraron que la alienación partidista vertical no tiene un impacto en la distribución del GNE de los ramos 33 y 28. Por lo tanto, se puede concluir que las decisiones del gobierno federal no están influidas por los aspectos de tipo partidista, al menos no en las variables aquí estudiadas. Aunque esto podría ser una buena noticia, los efectos del índice de marginación y del PIB estatal tuvieron un signo opuesto al que se esperaría, lo cual podría ser otra razón para revisar las fórmulas de distribución de los fondos que componen al Ramo 33 (y al Ramo 28).

18 Aspecto que ha sido planteado en la compilación de Chiapa y Velázquez (2011) y por Urzúa y Velázquez (2018)

19 Sin embargo, el Ramo 23 no cuenta con una normatividad que regule su distribución, como sucede con el Ramo 33. Además, el estudio de México Evalúa no controló otras variables socioeconómicas. 
Ya que esta investigación se enfocó en los montos totales del Ramo 33, queda como tarea pendiente analizar cuál es el comportamiento de cada fondo que lo compone. Esto permitiría identificar no sólo su magnitud, sino también determinar si su distribución también es ajena a cuestiones partidistas, sobre todo por las críticas que han recibido sus fórmulas (ASF, 2013). Finalmente, es preciso indagar por qué el Ramo 33 presenta más sobreejercicios mientras que el Ramo 28 presenta más subejercicios.

\section{Referencias}

Arechederra, F., y Carbajal, A. (2017). Errores estadísticos en la Ley de Coordinación Fiscal de México: una nota. Estudios Económicos, 32(2), 317-345.

Argáez, J. (2016). El papel moderador de los congresos locales sobre el ciclo político presupuestal oportunista en los estados mexicanos. Gestión y Política Pública, 25(2), 525-549.

Armesto, M. , y Olmeda, J. (2017). La recentralización y los gobernadores: ¿por qué no siempre se oponen? Analizando el caso de México. Foro Internacional, 57(1), 109-148.

Auditoría Superior de la Federación (ASF). (2013). Diagnóstico sobre la opacidad en el gasto federalizado. Ciudad de México: Auditoría Superior de la Federación, Cámara de Diputados.

Auditoría Superior de la Federación (ASF). (2018). Participaciones federales a entidades federativas y municipios. Auditoría especial de gasto federalizado. Ciudad de México: Auditoría Superior de la Federación, Cámara de Diputados.

Benton, A. (2019). Party leader or party reputation concerns? How vertical partisan alignment reins in subnational fiscal profligacy. The Journal of Politics, 81(1), 201-214. doi: 10.1086/700201

Bove, V., Efthyvoulou, G., y Navas, A. (2017). Political cycles in public expenditure: Butter vs guns. Journal of Comparative Economics, 45(3), 582-604. doi: 10.1016/j.jce.2016.03.004

Bulman-Pozen, J. (2014). Partisan federalism. Harvard Law Review, 127, 1097 1146. doi: 10.2139/ssrn.2291000

Busmail, A., y Miño, J. (2016). Estrategias partidistas y cooperación entre niveles de gobierno durante la presidencia de Felipe Calderón. En N. Loza e I. Méndez (coords.), Poderes y democracias. La política subnacional en México (pp. 113-130). Ciudad de México: Flacso-México.

Cabrero, E. (2013). Fiscal federalism in Mexico: distortions and structural traps. Urban Public Economics Review, 18, 12-36.

Chiapa, C., y Velázquez, C. (2011). Evaluación del Ramo 33. En C. Chiapa y C. Velázquez (coords.), Estudios del Ramo 33 (pp. 17-64). Ciudad de México: El Colegio de México.

Consejo Nacional de Evaluación de la Política de Desarrollo Social (CONEVAL). (2011). El Ramo 33 en el desarrollo social en México: evaluación de ocho fondos de política pública. Ciudad de México: CONEVAL. 
Consejo Nacional de Población (CONAPO). (2019a). Datos abiertos del índice de marginación. Recuperado de http://www.conapo.gob.mx/es/CONAPO/ Datos_Abiertos_del_Indice_de_Marginacion

Consejo Nacional de Población (CONAPO). (2019b). Situación demográfica y proyecciones de población. Recuperado de http://www.conapo.gob.mx/es/ CONAPO/Publicaciones

Diaz-Cayeros, A. (1997). Asignación política de recursos en el federalismo mexicano: incentivos y limitaciones. Perfiles Latinoamericanos, 10, 35-73.

Diaz-Cayeros, A., y Magaloni, B. (1998). Autoridad presupuestal del poder legislativo en México: una primera aproximación. Política y Gobierno, 5(2), 503-528.

Esselment, A. (2012). A little help from my friends: the partisan factor and intergovernmental negotiations in Canada. Publius: The Journal of Federalism, 43, 701-727. https://doi.org/10.1093/publius/pjs041

Flamand, L. (2006). El juego de la distribución de recursos en un sistema federal. La influencia del gobierno dividido verticalmente en la asignación de fondos federales a los estados mexicanos. Política y Gobierno, 13(2), 315359.

Gámez, C., e Ibarra-Yúnez, A. (2009). El ciclo político oportunista y el gasto de los estados mexicanos. Gestión y Política Pública, 18(1), 39-65.

Garman, C., Haggard, S., y Willis, E. (2001). Fiscal decentralization: a political theory with Latin American cases. World Politics, 53(2), 205-236. doi: 10.1353/wp.2001.0002

Guerrero, E. (2011). Determinantes del subejercicio presupuestal en el Fondo de Aportaciones para la Seguridad Pública (FASP) del Ramo 33. En C. Chiapa y C. Velázquez (coords.), Estudios del Ramo 33 (pp. 227-261). Ciudad de México: El Colegio de México.

Ibarra, J. (2013). Entorno político y dependencia financiera de los estados mexicanos. Gestión y Política Pública, 22(1), 3-44.

Ibarra, J., y Santos, C. (2018). Candidatos de coaliciones políticas e indicadores del peso de la deuda de los estados mexicanos. En A. Mendoza (coord.), Los incentivos perversos del federalismo fiscal mexicano (pp. 163-198). México: Fondo de Cultura Económica.

Instituto Mexicano para la Competitividad (IMCO). (2010). La caja negra del gasto público. Recuperado de http://imco.org.mx/indice_estatal_2010/ PDFS/Lacajanegradelgastopublico.pdf

Instituto Nacional de Estadística y Geografía (INEGI). (2019). Estadística de finanzas públicas estatales y municipales. Recuperado de https://www.inegi. org. mx/sistemas/olap/Proyectos/bd/continuas/finanzaspublicas/FPMun.asp?s=est\&c=11289\&proy=efipem_fmun

Jones, M. P., Sanguinetti, P., y Tommasi, M. (2000). Politics, institutions, and fiscal performance in a federal system: an analysis of the Argentine provinces. Journal of Development Economics, 61(2), 305-333. doi: 10.1016/ S0304-3878(00)00059-6

Katsimi, M., y Sarantides, V. (2012). Do elections affect the composition of fiscal policy in developed, established democracies? Public Choice, 151(1), 325-362. doi: 10.1007/s11127-010-9749-8 
Krause, G., y Bowman, A. (2005). Adverse selection, political parties, and policy delegation in the American Federal System. Journal of Law, Economics and Organization, 21, 359-387. doi: 10.1093/jleo/ewi021

Ley de Coordinación Fiscal. (1978). Diario Oficial de la Federación, Ciudad de México, México, 27 de diciembre de 1978. Recuperado de http://www.diputados.gob.mx/LeyesBiblio/pdf/31_300118.pdf

México Evalúa. (2014). Descifrando la caja negra. Ciudad de México: México Evalúa.

México Evalúa. (2018a). Arquitectura del Ramo 23. Ciudad de México: México Evalúa.

México Evalúa. (2018b). Léase si quiere gobernar (en serio). Ciudad de México: México Evalúa.

Molinar, J., y Weldon, J. (1994). Programa Nacional de Solidaridad: Determinantes partidistas y consecuencias electorales. Estudios Sociológicos, 12(34), 155-181.

Nordhaus, W. D. (1975). The Political Business Cycle. The Review of Economic Studies, 42(2), 169-190. doi: 10.2307/2296528

Núñez, L. (2017). ¿Y dónde quedó la bolita? Presupuesto de egresos ficticio. Ciudad de México: Aguilar.

Organisation for Economic Co-operation and Development (OECD). (2016). Fiscal Federalism 2016. Making Decentralisation Work. ¿Ciudad? OECD Publishing.

Organismos Públicos Locales Electorales (OPLES). Datos electorales. Páginas web de cada estado.

Organización de las Naciones Unidas (ONU). (2017). Informe de los objetivos de desarrollo sostenible 2017. Organización de Naciones Unidas. Recuperado de https://unstats.un.org/sdgs/files/report/2017/TheSustainableDevelopmentGoalsReport2017_Spanish.pdf

Peña, J. (2011). Manual de transferencias federales para municipios. Ciudad de México: Instituto Nacional para el Federalismo y el Desarrollo Municipal.

Public Expenditure and Financial Accountability (PEFA). (2012). Province of Santa Fe. Republic of Argentina. Public Financial Management Assessment. Recuperado de https://pefa.org/assessment/ar-santa-fe-province-jul12pfmpr-sn-public-en

Public Expenditure and Financial Accountability (PEFA). (2016). Marco de referencia para la evaluación de la gestión de las finanzas públicas. Recuperado de https://pefa.org/sites/default/files/PEFA\%20Framework_Spanish.pdf

Ramírez, R., y Erquizio, A. (2012). Análisis del ciclo político electoral a partir de variables de gasto público por entidad federativa en México, 1993-2009. Paradigma Económico, 4(2), 5-27.

Read, J. (2016). Constitutionalizing the dispute: federalism in hyper-partisan times. Publius: The Journal of Federalism, 46, pjw012. doi: 10.1093/publius/pjw012

Riker, W., y Schaps, R. (1957). Disharmony in federal government. Behavioral Science, 2(4), 276-290. doi: 10.1002/bs.3830020405 
Rodden, J. (2001). Creating a more perfect union: political parties and the reform of federal systems. Recuperado de http://web.mit.edu/jrodden/ www/materials/moreperfect.pdf

Rodden, J., y Wibbels, E. (2002). Beyond the fiction of federalism: macroeconomic management in multitiered systems. World Politics, 54(4), 494-531. doi: 10.1353/wp.2002.0016

Secretaría de Hacienda y Crédito Público (SHCP). (2019). Cuenta Pública. Recuperado de

Shi, M., y Svensson, J. (2006). Political budget cycles: do they differ across countries and why? Journal of Public Economics, 90(8), 1367-1389. doi: 10.1016/j.jpubeco.2005.09.009

Sobarzo, H. (2008). Factores clave para el fortalecimiento del federalismo en México: Una visión desde las entidades federativas. En Federalismo y descentralización (pp. 137-169). México: Secretariado Técnico al Servicio de los Gobiernos Estatales, A. C.

Sobarzo, H., Ruiz, L., y García, M. (2011). Hacia una caracterización de las determinantes del gasto estatal en México. En C. Chiapa y C. Velázquez (coords.), Estudios del Ramo 33 (pp. 65-91). Ciudad de México: El Colegio de México.

Trejo, G., y Ley, S. (2016). Federalismo, drogas y violencia. Por qué el conflicto partidista intergubernamental estimuló la violencia del narcotráfico en México. Política y Gobierno, 23(1), 11-56.

Ugalde, C. (2018). La negociación política del presupuesto, 1997-2018. Ciudad de México: Integralia.

Urzúa, C., y Velázquez, A. (2018). Errores fiscales en el ámbito federal. En A. Mendoza (coord.), Los incentivos perversos del federalismo fiscal mexicano (pp. 43-63). México: Fondo de Cultura Económica.

Velázquez, C. (2006). Determinantes del gasto estatal en México. Gestión y Política Pública, 15(1), 83-109.

Vergne, C. (2009). Democracy, elections and allocation of public expenditures in developing countries. European Journal of Political Economy, 25(1), 6377. doi: 10.1016/j.ejpoleco.2008.09.003

Zepeda, G. (2011). Trayectoria, criterios de asignación y destino del fondo de aportaciones para la seguridad pública, y dificultades para el control, seguimiento, evaluación y fiscalización de sus recursos. En C. Chiapa y C. Velázquez (coords.), Estudios del Ramo 33 (pp. 262-288). Ciudad de México: El Colegio de México. 